\title{
UNIVERSUM
}

\section{"LA IMAGEN SUPERVIVIENTE". ' LA FOTOGRAFÍA DOCUMENTAL EN EL TESTIMONIO CHILENO CONTEMPORÁNEO (JAVIER REBOLLEDO Y NANCY GUZMÁN) ${ }^{2}$}

\author{
"The surviving image". Documentary photography in contemporary Chilean testimony (Javier Rebolledo \\ and Nancy Guzmán)
}

\author{
Daniuska González ${ }^{\text {( }}$ \\ Universidad de Playa Ancha, Chile.

\section{RESUMEN}

'Departamento de Literatura y Lingüística, Facultad de Humanidades/Centro de Estudios Avanzados,

En el presente artículo se pretenderá una lectura de algunas de las fotografías documentales que acompañan los testimonios El despertar de los cuervos. Tejas Verdes el origen del exterminio en Chile (2013) de Javier Rebolledo e Ingrid Olderock. La mujer de los perros (2014) de Nancy Guzmán, con el objetivo de observar cómo estas refuerzan la palabra testimoniante y contribuyen a completar una narratología memorística sobre dos lugares donde se violaron sistemáticamente los derechos humanos durante la dictadura militar de Augusto Pinochet: el campo concentracionario Tejas Verdes y la casa conocida como la 'Venda Sexy'. Para soportar el análisis de las series fotográficas sobre los rostros de los torturadores y los instructores en Tejas Verdes, así como de las cuatro imágenes de la vivienda santiaguina, se recurrirá a textos teóricos de Claudia Feld, Diamela Eltit, Jaume Peris Blanes, Joan Fontcuberta y Georges Didi-Huberman. Este diálogo permitirá entender cómo la fotografía documental, aquella sin intenciones artísticas, constituye una fuente de valor informativo y una impronta de constancia de la memoria para aproximarse a un momento histórico que no ha podido cerrarse debido a la magnitud del horror incrustado en él.

PALABRAS CLAVE: testimonio; fotografía; dictadura; violencia; Chile.

\section{ABSTRACT}

In this article, a reading will be attempted of some documentary pictures that accompany the testimonies in El despertar de los cuervos. Tejas verdes el origen del exterminio en Chile (2ог3) by Javier Rebolledo and Ingrid Olderock. La mujer de los perros (2014) by Nancy Guzmán, with the aim of observing how they reinforce the testimonial word and contribute to completing a memory narratology on two places where human rights were systematically violated during the military dictatorship of Augusto Pinochet: Tejas Verdes concentration camp and the house known as 'Venda Sexy'. Some theoretical texts will be used to support the analysis of the photographic series on the faces of the torturers and the instructors in Tejas Verdes, as well as the four images of the Santiago house, all of them by Claudia Feld, Diamela Eltit, Jaume Peris Blanes, Joan Fontcuberta and Georges Didi-Huberman. This dialogue will allow us to understand how a without artistic intentions photography like documentary photography constitutes a source of informative value and an imprint of constancy of memory to approach a historical moment that could not be closed due to the magnitude of the horror embedded in it.

KEYWORDS: testimony; photography; dictatorship; violence; Chile.

Fecha de Recepción

$$
\text { 2020-08-19 }
$$

\begin{tabular}{|c|}
\hline Fecha de Evaluación \\
\hline $2020-09-2 I$ \\
\hline
\end{tabular}

\section{Fecha de Aceptación}

$2020-10-27$

\footnotetext{
' En referencia al libro de Georges Didi-Huberman La imagen superviviente. Historia del arte y tiempo de los fantasmas según Aby Warburg (primera edición en francés, 2002). Para el presente artículo se trabajará con esta idea de 'imagen superviviente'.

${ }^{2}$ Este artículo se inscribe en el Fondecyt Regular 2019 № irgoz33: Los nudos de la memoria. El testimonio chileno y venezolano contemporáneo, del cual la autora es la Investigadora Responsable. El artículo se comenzó a pensar en 2019, a partir de algunas series fotográficas que se encuentran en la Biblioteca Nazionale Marciana de la ciudad de Venecia.
} 
En Chile ya entendemos que el acto de memorizar, de detallar, de agitar los tiempos se vuelve ciertamente conflictivo al intentar buscar en los pliegues del pasado aquellas circunstancias que permiten inferir los anudamientos que atraviesan culturalmente el presente.

(Emergencias, Diamela Eltit)

\section{VISUALIDAD DOCUMENTAL EN EL TESTIMONIO: ACOTACIONES NECESARIAS}

Unas imágenes pertenecen a rostros envejecidos que si se encontraran fuera del libro donde se agrupan, pudieran pensarse como parte de un grupo de sujetos fotografiados para algún trámite administrativo. Las otras, cuatro secuencias de una casa, el baño y las escaleras tanto hacia el piso superior como hacia el sótano. Nada las particulariza en su condición documental, pero esta visualidad anodina solo refiere apariencias. Las primeras fotos fijan las caras de los torturadores y los instructores del campo concentracionario Tejas Verdes, centro de detención, tortura y desaparición a partir del golpe de estado de 1973 y hasta mediados de 1974 , y que se insertan como pequeñas trazas en el testimonio El despertar de los cuervos. Tejas Verdes el origen del exterminio en Chile, de Javier Rebolledo (20r3); mientras que las segundas pertenecen a la 'Venda Sexy', otro de los lugares asociados a la represión militar, y que Nancy Guzmán (2014) integró al paisaje de terror de esa época, también a través del testimonio, en Ingrid Olderock. La mujer de los perros.

En un primer momento del presente artículo ${ }^{3}$ se pensó trabajar estas fotografías como pliegos testimoniales, es decir, asumir que operaban como dispositivos visuales testimoniales en idéntico nivel que ambos textos -que conforman una coral de voces que va desde las cuatro víctimas y un subteniente en el libro de Rebolledo hasta la propia Olderock en el de Guzmán-; sin embargo, lo impidió el carácter meramente documental, utilitario, que sirve como apoyatura visual mas no constituye un artefacto, lo cual definiría la carencia de una intención artística, de una convención facticia con entrada del elemento estético.

\footnotetext{
3 Sobre el Estado del Arte se señalan los siguientes textos académicos: Testimonios/documentación: apostillas a la memoria visual, de Gonzalo Leiva Quijada (2017); y los que se abordarán a lo largo de este artículo: De la prueba documental a la evocación subjetiva. Usos de la fotografía en las publicaciones sobre la represión chilena (2009) y Testimonio y visualidad: de la visión del ciego a las imágenes del vacío (2017), ambos de Jaume Peris Blanes; así como la tesis Literatura y visualidad. El libro fotográfico durante la dictadura chilena (1973-1989), trabajo de María Fernanda Piderit (2016) para optar al título de Magíster en Literaturas Española y Latinoamericana de la Universidad de Buenos Aires. Acerca de los autores Javier Rebolledo y Nancy Guzmán se mencionan El periodismo narrativo español y latinoamericano. Influencias, temáticas, publicaciones y puntos de vista de una generación de autores, de Dolors Palau-Sampio y Antonio Cuartero-Naranjo (2018), y los artículos de la autora del presente texto: Corriendo las vallas alrededor del testimonio: reescrituras del género a partir del pacto facticio y la voz medial del periodista/narrador (2020) y El simulacro de la víctima. 'Máquina mitológica', violencia y poder en los testimonios Así mataron a Danilo Anderson de Alfredo Meza e Ingrid Olderock. La mujer de los perros de Nancy Guzmán (202I), este último en coautoría con Claire Mercier.
} 
En definitiva, son fotos con fines prácticos, esto en coincidencia con Joan Fontcuberta (2015), útiles en el carácter de uso/desuso de la imagen en esta época de globalización y que responden a "unas vivencias, que se transmiten, [y] se comparten" (p. 3i), en este caso confinadas a estos libros testimoniales ${ }^{4}$ como columnas de soporte y cuya función se origina puntualmente por la ampliación de acontecimientos traumáticos y/o por la operación de armar identidades problemáticas, comprometidas con crímenes de lesa humanidad que requieren su particularización. "El patrimonio histórico de la fotografía sigue siendo lo documental" (p. i85), por esta razón su importancia como apoyaturas para otros discursos, el testimonial en el corpus seleccionado.

Por su parte, para Boris Kossoy (200I), la fotografía documental acompaña los procesos históricos como visualidad constitutiva, parte involucrada para mirarlos y preservarlos: "El artefacto fotográfico, a través de la materia (que le da cuerpo) y de su expresión (el registro visual en él contenido) constituye una fuente histórica" (p. 38); mientras que Claudia Feld (2015) unifica la palabra testimoniante con las imágenes y encuentra en este cruce un "rol [...] en tanto agentes de prueba y veridicción, primero, y como soportes del recuerdo después" (p. 689), con lo cual se completa la visibilización de un contexto de violencia de Estado, la última dictadura militar argentina (1976-1983) en el caso que la autora analiza, no solo mediante la voz sino también a través de otro lenguaje, el visual, que permite el reforzamiento para ambos discursos (p. 69o).

De ahí que la aproximación se produzca a partir del vínculo entre testimonio e imagen en dos series fotográficas en el libro de Rebolledo y las cuatro imágenes mencionadas del texto de Guzmán, viendo el enriquecimiento textual del primero con la inclusión de las fotografías, pues en situaciones límite como las experimentadas en espacios concentracionarios, se necesita tener a mano todas las herramientas posibles, entre ellas material visual sin propósito artístico, que enuncien, aunque sea fragmentariamente, con una exposición simple desde el presente, la normalización de la nuda vida y las estrategias del terror como práctica recurrente de la violencia política durante la dictadura militar pinochetista.

Pero antes de continuar una precisión sobre la crítica a las obras de Rebolledo y Guzmán como portadas, entrevistas y notas de prensa y de venta-, leídas como investigaciones periodísticas y no como pertenecientes al género testimonial. Para la autora de este artículo, abordarlas desde este último formato permite ampliar los márgenes del dispositivo testimonio, no solo desde el punto de vista interdisciplinario (en este caso literatura y periodismo) sino también en cuanto

\footnotetext{
${ }^{4}$ En el caso de Rebolledo también implicaría documentos probatorios del sistema de justicia.
} 
contenedor discursivo que evade límites como el tradicional de una voz que testifica mientras otra escucha, para convertirse en un pliego que aceptaría otras textualidades, otras formas de construirse.

De esta manera, partiendo del testimonio -importante este punto de arrancada que marcaría el predominio del género- de Feliciano Cerda, Patricio Salvo, Anatolio Zárate, Ana Becerra y Olga Letelier en el libro de Rebolledo y de Ingrid Olderock en el de Guzmán, sujeto atravesada, además, por otras voces testimoniantes, ambos autores hilvanan un relato que mantiene la condición de verificación (los hechos ocurrieron realmente) con la de facticidad (intervención ficcional de los mismos), al tiempo que ellos se introducen en las historias con sus propias voces, superando el carácter de reporteros y transformándose en periodistas-narradores. Esta visión se adosaría al planteamiento de Carolina Pizarro Cortés y José Santos Herceg (2019) de integrarse al "campo testimonial rico, complejo, polifónico, que se aproxima a la historia reciente de Chile de distintas formas" (p. 248). En sentido general, una cercanía a la condición testimonial desde varios puntos de vista, discursividades y sujetos testimoniantes.

En una vuelta al elemento fotográfico, en el texto De la prueba documental a la evocación subjetiva. Usos de la fotografía en las publicaciones sobre la represión chilena, el investigador Jaume Peris Blanes (2009) se detiene en un momento específico de las imágenes relacionadas con la violencia ejercida por la dictadura militar, cuando estas se desvincularon de un primer sentido, aquel "del paradigma de la denuncia política", para acceder al de "su incorporación al paradigma de la memoria" (p. 86). Este cambio de uso tiene a la fotografía documental en su centro, de ahí que interese imbricar este texto con el de Testimonio y visualidad: de la visión del ciego a las imágenes del vacío (20I7), también de este autor, con lo cual se produce una mirada teórica que puede vaciarse en el conjunto de fotografías de los libros testimoniales de Rebolledo y Guzmán.

Por un lado, para Peris Blanes, en el mapa histórico-geográfico chileno de la postdictadura, se instaló una carencia de señales contundentes sobre los lugares donde se torturó -como Tejas Verdes y la 'Venda Sexy' en el tema ocupado- que se integrarían a las dinámicas neoliberales de blanqueamiento sobre la historia reciente; $y$, por otro, faltaría una imagen plena, que por sí misma pueda contar, y que no deje, debido a su cualidad de incompletud, la interpretación al espectador (en este caso del lector), al que corresponderá vincular estos sitios, problemáticos para las políticas de concertación después del periodo dictatorial, con las formas como el arte se apropia de ellos y los somete a su enunciado de representación. 
Las imágenes actúan como constancias contra la desmemoria a la que alude Peris Blanes en ambos artículos, al colocar un rostro al torturador, individualizarlo y, por ende, aislarlo de la cadena de mando militar tan manida como pretexto para la disolución de responsabilidades; o vuelven a poner en circulación lugares de confinamiento, violaciones y asesinato. Ineludiblemente, estas fotos adquieren el estatuto de "marcas simbólicas" (Peris Blanes, 2017, p. 88) sin importar su adscripción o no al artificio artístico.

Directamente se apuntaría a la "imagen superviviente" en el sentido huberminiano, aquella que renace una y otra vez en contextos diferentes, como un pliego iconográfico cuya lectura y reconstrucción se dilata a lo largo del tiempo, con una utilidad por encima de la cronología de origen al funcionar como una "crónica" (2018, p. II) para el "análisis de [todos] los tiempos", periodos en los cuales se inserta en tanto "corpus de saber" (p. II, cursivas en el texto original), una textualidad visual que aporta nuevas notas, conocimientos o singularidades, como en los dos textos testimoniales que se analizarán.

La 'imagen superviviente' instaura un ciclo que trae el hecho del pasado hacia el presente y lo reconsidera como material dúctil, dispositivo de saber, que descifra al primero al añadir nuevas perspectivas y modos de contacto con el público. Al adentrarse en la propuesta de Aby Warburg (20r8), centro de su extenso texto, el teórico francés consigue mirar la imagen como un proceso que integra "plasticidad, [...] movilidad, [...] metamorfosis" (p. 417), con lo cual asentaría su naturaleza permutable. Siguiendo este razonamiento, se tendría, entonces, un conjunto de fotografías que circulan del pasado al presente, que borran los límites del encasillamiento puramente cronológico y que, mediante su agrupamiento, detentan la capacidad de permitir un repaso del acontecimiento ocurrido a partir de la retina de un lector/espectador actual, el cual se encargará de reactualizarlo.

\section{LOS ROSTROS VISUALES DEL HORROR. FOTOGRAFÍAS DE TORTURADORES E INSTRUCTORES EN EL TESTIMONIO DE REBOLLEDO}

Como se había adelantado, en este artículo interesa la imagen documental en tanto "marca simbólica" a la cual se refirió Peris Blanes (2017). En El despertar de los cuervos, las fotos se vinculan a partir de la serialidad de una galería que identifica el rostro actual de los victimarios ${ }^{5}$ de Tejas

\footnotetext{
5 Aunque no se trabajarán en el presente artículo, en el libro también aparecen las fotografías de los rostros de otros victimarios: ocho autoridades de Tejas Verdes, entre estos, nuevamente, Manuel Contreras con uniforme militar; tres de los integrantes de su grupo más cercano; veintidós médicos de clínicas de la DINA y la CNI; cinco enfermeras y dos aspirantes a ingresar en el regimiento para la carrera militar.
} 
Verdes a través de cuadros tamaño carné para las fichas adjuntadas a las investigaciones judiciales. Fotografías anodinas, en blanco y negro, que elaboran una narrativa visual que colocan una cara, una gestualidad, a la palabra testimoniante, que incluye hasta la media sonrisa del torturador que se siente por encima de la ley.

Esta serialidad se cobija en uno de los enunciados de Didi-Huberman (20I8) acerca del significado de los agrupamientos fotográficos de las "imágenes supervivientes", que, al quedar engrapados en un tiempo histórico, producen un efecto "acumulante" (p. 4I2) sobre acontecimientos y sujetos, definiendo, además, la mirada que recae sobre ellos, trasvasada por esa fuerza acumulativa que produce una visión de conjunto, sin que se pierda por esto la huella de individualización. Con lo serial se dibuja un trazado grupal que posibilita asomarse tanto al pasado como al presente en el cual reaparece, como una bisagra entre ambos.

Con lo anterior se significa que, en el corpus, las fotografías también devienen dispositivos que atestiguan una individualidad $-\mathrm{y}$, por tanto, una responsabilidad- dentro de un contexto colectivo de violencia política. Como la letra impresa (los testimonios), los retratos están invitando al lector a observarlos como si pasara el álbum de identificación que utiliza la policía judicial, rostros que pertenecieron a torturadores que estuvieron en lugares vinculados al vejamen y la desaparición, como el campo concentracionario Tejas Verdes, y que cometieron crímenes de lesa humanidad.

Estos son rostros "sumergid[o]s en el lugar más insondable de un subpoder omnisciente, [y] rondan el imaginario colectivo chileno", como escribió Diamela Eltit (2014, p. 53); sin embargo, como la palabra del testigo, constituyen "imágenes supervivientes" de esa época, que retornan, y se convierten en instrumentos testificantes de su horror en el presente.

Por esto El despertar de los cuervos de Rebolledo ${ }^{6}$ resulta el texto que más aporta. Si bien habría que reconocer la entrada de una fotografía por cada uno de los cinco sujetos testimoniantes principales (las víctimas Anatolio Zárate, Feliciano Cerda, Olga Letelier y Olga Becerra, y el subteniente Patricio Salvo), está intersticiado por los rostros de los victimarios que pasaron por el recinto de Tejas Verdes, el sitio de 'origen del exterminio en Chile', como se titula el libro. Ahora viejos, algunos ya fallecidos, arman una galería que no por parecer inofensiva -en el sentido de su

\footnotetext{
${ }^{6}$ Con menos profusión que en el texto analizado, en la parte central de La danza de los cuervos. El destino final de los detenidos desaparecidos (2012), Rebolledo utiliza una serie fotográfica del rostro de cuarenta y cinco implicados en el Cuartel Simón Bolívar, colocando así una identidad que, dada la misteriosa existencia de este lugar, se convierte en una revelación junto con los testimonios orales. Sin embargo, en el caso de A la sombra de los cuerpos. Los cómplices civiles de la dictadura, el menos testimonial de la 'trilogía de los cuervos', las imágenes fotográficas atraviesan todo el libro.
} 
reconocimiento y fichaje por la justicia- deja de menos su estatuto de denuncia, su "valor [...] en cuanto a identificar a los agentes de la represión clandestina" (Feld, 2015, pp. 698-699).

Bajo esta premisa habría que leer la serie Equipo de torturadores (fotos actuales). La primera foto toma la cara de Manuel Contreras Sepúlveda, fallecido en 2015, quien ejerció como director del Regimiento de Ingenieros Tejas Verdes, luego como director de la Dirección de Inteligencia Nacional (DINA) y General de Ejército, y junto con Augusto Pinochet, autor intelectual del genocidio ocurrido en dictadura. No obstante, lo que saca a la luz este libro es su participación directa en la tortura, por ejemplo, cuando al prisionero Feliciano Cerda lo violaron en su presencia, por instrucciones de él, y escuchó su voz, esa que "ordenó al tutor que lo vistiera [...]. Años después, viendo la televisión, asoció esa voz con la imagen y la voz del director de la DINA, Manuel Contreras" (Rebolledo, 2013, p. 295).

En las fotos que acompañan esta serie, los sujetos miran de frente a la cámara, algunos retadores, la mayoría con expresiones sombrías y descreídas de este momento de fijación fotográfica, pero Contreras, quien representa para Eltit (2014) una "imagen de duelo, muerte y de destrucción" (p. 53), se ladea y la pose pertenece a alguien que "no da la cara', que no se siente interpelado y que, por ende, no atestiguará jamás, como efectivamente ocurrió. Como si lo hubieran arrastrado sin su consentimiento, obligado a permanecer dentro del encuadre.

Más allá de esta suerte de desafío, la imagen instala una identidad que testimonia al poner una fisonomía al individuo detrás de las sesiones de tortura y terror. En la foto, la cabeza altanera de Contreras parece remitir al espacio de poder que ocupó en el pasado, como si, parafraseando a la autora de Emergencias, volviera a aparecer y volviera a acontecer, "imagen sobreviviente" que aloja el miedo una y otra vez, "un miedo que se sabe tiene un correlato con la más tangible realidad" (Eltit, 2014, p. 53). La placa fotográfica lo revela en esta pose de superioridad, ajeno a las expresiones de los otros diez victimarios, rostros apagados y serios, algunos de avanzada edad, todos retirados de las funciones militares en el presente.

Cabría la interrogante de Hanna Arendt (1963) acerca de la naturaleza del mal y su banalidad burocrática, que no se responde, obviamente, al observar estos encuadres en blanco y negro donde las caras proyectan una normalidad aplastante. Sin embargo, a cada una correspondió una función dentro del campo Tejas Verdes. Estas fotografías se convierten, al decir de Kossoy, en "un documento visual, cuyo contenido es [...] revelador de informaciones" (200I, p. 23), se agregaría que tanto como los testimonios que contiene el texto. Inclusive dos sujetos, Gregorio del Carmen 
Romero Hernández y David Gustavo Pedreros Pineda, se particularizan como testigos con datos valiosos de primera mano para Rebolledo.

Si bien estas identidades están delimitadas, son numerosas a nivel de descripciones y datos documentales y se reproducen unas detrás de otras, pero los retratos las fijan como dispositivos en sí mismos, trazas visuales más concretas sobre los participantes y la violencia que ejercieron, como plantea Feld para el caso de la ESMA en Argentina:

Las fotos del personal represivo [...] no marca[n] la diferencia de responsabilidades; sin embargo, esta suerte de "muestrario" ofrece el dato contundente de la cantidad de personal dedicado al funcionamiento del centro clandestino. Además, las fotos identificatorias, unidas al nombre y a los datos brindados por Basterra, generan un efecto de "revelación" sobre lo clandestino. Pero una revelación que se produce de un modo paradójico: las caras de los verdugos ocultos se hacen visibles, pero sin un contexto espacial en el que se las pueda ubicar. (2015: 700)

Como se deriva de la cita, esta galería de fotos en El despertar de los cuervos converge en un epicentro: dentro del testimonio trabajado, se textualizan como un material de soporte para el escrito. Alrededor de las voces testimoniantes surgen numerosos nombres, unos seguidos de otros, y llega un momento de tanta saturación que se necesita poner un rostro a esta retahíla de violencia, personalizarla.

El recurso visual, entonces, legitima el acontecimiento testificado mediante la palabra. Esto forma parte de una dinámica de las imágenes que, para Fontcuberta "se ponen al servicio de una reflexión sobre la memoria" (2015, p. I04) y esta idea viene a colación para detenerse en este documento fotográfico que se aleja de la intencionalidad artística y que se centra en un fin utilitario, sin mayor presunción que aquella de la lente detenida sobre un sujeto con responsabilidad en un contexto de violencia política, integrándola a las recuperaciones que demanda la memoria histórica.

La cámara "muestra y describe" (Fontcuberta, 2015, p. I08), después pasa a un segundo momento cuando narra y transforma su producto en un relato por sí mismo. Estas fotos seriadas quedan en el primer intervalo, en el de mostrar y describir para acompañar, en este caso, al formato testimonial, pero sin que esta acción utilitaria socave la contribución al objetivo: con estos rostros se complementa la circulación de aquellas experiencias traumáticas, que enhebra el testimonio de los sobrevivientes de Tejas Verdes con estas fotos que singularizan a sus victimarios y que, como apuntó Peris Blanes con respecto a las fotos de los desaparecidos, "también [...] trae al recuerdo la imagen de un tiempo otro que ya no es" (2009, p. 95). 
Pero una segunda galería acompaña a la anterior, una con los rostros de los sujetos que se desempeñaron como instructores, "maestros" para enseñar, entre otras, las técnicas de tortura. Esta serie valida la presencia en el lugar de tres nombres cuya carrera se hizo sobre el crimen y luego de terminado el periodo dictatorial sobre la impunidad, piezas claves para entender el funcionamiento de la lógica concentracionaria de la DINA: Ricardo Lawrence Mires, Miguel Krassnoff Marchenko e Ingrid Olderock.

Para este artículo impresiona el sonriente Krassnoff Marchenko, mientras las demás imágenes borronean gestualidades adustas, ojos apagados o sorprendidos, esto último como si no creyeran todavía en su exposición como sujetos responsables del horror político. A diferencia de Contreras Sepúlveda que la evade, él mira directo a la cámara, levanta la cara con orgullo y la sonrisa se dibuja en sus labios. Viene a colación apegarse a la idea de Fontcuberta acerca de que ese rostro fotografiado:

... es el espejo del alma, el lugar a la vez más íntimo y más exterior del sujeto, la pantalla en la que se funde su interioridad psicológica con las coerciones a que le somete la vida pública. El rostro es, a la vez, la sede de la revelación y de la simulación, de la indiscreción y de la ocultación, de la espontaneidad y del engaño, es decir, de todo aquello que permite la configuración de la identidad. (2015:2I)

Esta cita desgaja dos consideraciones. La primera, la más evidente, se relaciona con una puesta en escena visual donde el sujeto sociópata carece de empatía y sentido de la responsabilidad por sus acciones. Retomando una metáfora de Eltit, él es la negrura que materializa la placa fotográfica. Parece posar para un público, como parte de una tramoya que le produce hilaridad. La segunda resulta más inquietante porque deriva una constancia visual sobre el personaje y sus actos que correría paralelo a lo que se testifica mediante la palabra: la foto lo sitúa en el lugar, allí, en "el primer campo de entrenamiento para agentes de la DINA", al lado del "centro de interrogatorio que funcionaba en el Regimiento de Ingenieros Tejas Verdes" y como parte de los "oficiales de las distintas ramas, quienes luego encabezaron las principales agrupaciones operativas de la DINA" (Rebolledo, 2013, p. I23).

En Tejas Verdes, Krassnoff Marchenko se integró obedientemente -se añadiría que con sadismo- a la maquinaria del terror estatal y se convirtió en una de las piezas principales, que velaba por la disposición de sus alumnos, al tiempo que apoyaba la receta de Luis Francisco Carevic, al mando del campo, para adoctrinar a los reclusos: "golpes, aislamiento, tortura y rigidez" (Rebolledo, 20I3, p. I22). Como sus compañeros de armas, ejecutó "la violencia de Estado [...] [que produjo] cuerpos abiertos, fragmentados, desestructurados, desfigurativizados [...] [por el] efecto de 
la tortura", como apuntó Peris Blanes (2017, p. 82) en su texto. A los testimonios sobrecogedores de las víctimas sobrevivientes (Zárate, Cerda, Letelier y Becerra), trasvasados, en su mayoría, por "el predominio del lenguaje directo, y, por otra, abundan[te] [de] anclajes que garantizan referencialidad" (Pizarro Cortés y Santos Herceg, 2019, p. 25I), se contrasta la imagen risueña y descarada de Krassnoff Marchenko, cuyo sentido solo puede leerse desde la indiferencia hacia los crímenes que cometió y justificó, aún en la actualidad desde su cómodo confinamiento en Punta Peuco.

Como en el ciclo huberminiano de la "imagen superviviente", esta foto vuelve a instalar el acontecimiento, el gesto facial del implicado se repotencia en el acto pasado de la tortura y constituye un abismo fotográfico en sí mismo, que "[s]señala que, una vez más, la fotografía permit[e] a la vez rememorar cada versión y no detenerse en ella de manera definitiva" (Didi-Huberman, 2018, p. 417).

\section{LAS VENDAS DEL DOCUMENTO VISUAL. FOTOGRAFÍAS DE LA "VENDA SEXY" EN EL TESTIMONIO DE GUZMÁN}

Feld (2015) puntualiza que "los sitios fotografiados sin personas, hace que el testimonio verbal sea clave para otorgar sentido a lo que se ve: estas fotos ofrecen una topografía en suspenso, que sólo podía completarse con el relato verbal" (p. 699, cursivas en el texto original). Desde esta postura se entrelazan los testimonios en Ingrid Olderock. La mujer de los perros, entre ellos el desgarrador de Beatriz Bataszew Contreras, detenida el I2 de diciembre de I974 por la DINA y llevada al centro de reclusión la 'Venda Sexy', para Guzmán (2014) “el centro de torturas más inquietante y desconocido de la época de la dictadura militar" (p. 2); y las cuatro fotografías actuales de este lugar, que, recordando a Fontcuberta a partir de Benjamin, "hace[n] historiable un acontecimiento" (Fontcuberta, 2015, p. 17).

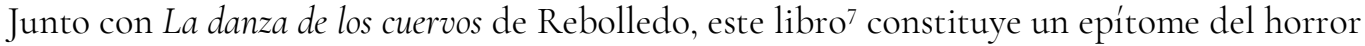
vinculado a la violencia política, cuando el Estado impone la fuerza como lógica del acontecer cotidiano y la normaliza. Todos los testimonios, comenzando por el principal, el de la agente de la DINA Olderock que da cuerpo a la historia facticia construida por la autora, hasta los de las víctimas, están enfocados en esta dirección.

\footnotetext{
7 Como en el caso de Osvaldo Romo Mena, alias 'Guatón Romo', que la propia Guzmán recogió en Romo: confesiones de un torturador (2000) y en la segunda edición de este libro, Romo. El pasado en el presente (2019).
} 
"Ahí llego vendada, [...], me preguntan algunos datos básicos, [...] y me llevan al subterráneo, a la tortura. [...]. Normalmente, en este subterráneo había cuatro, cinco o seis individuos que realizaban las torturas, ahí también estaba el perro 'Volodia" (Guzmán, 2014, p. 72), trata de verbalizar el dolor Bataszew Contreras, pero su testimonio se traba, queda incompleto, pese a que arroja luz sobre procesos traumáticos que ensamblan piezas centrales frente a "las lógicas del olvido y la indiferencia" (Peris Blanes, 20I7, p. 88) posteriores a la dictadura.

Entonces se produce un enclave que potencia al de la palabra testimoniante, cuando esta no puede dar cuenta del acontecimiento y se recurre a las imágenes como otro formato que visibiliza una constancia difícil de aprehensión, en este caso la imposibilidad de decir de los sujetos sometidos a la tortura, sobre todo sexual: "Para muchos de quienes pasamos por esta Venda, por el tipo de torturas sexuales, nos ha costado testimoniar y eso ha representado una dificultad" (Bataszew en Guzmán, 20I4, p. 77).

A diferencia de las fotografías de los implicados en la tortura en Tejas Verdes a quienes se necesitaba individualizar con el rostro, en el texto de Guzmán se requiere otro tipo de documentalidad visual que funcione en paralelo a las palabras de las víctimas o de Olderock, pues, si bien "el testimonio le otorga inteligiblidad a la foto; es la foto la que colabora para otorgarle legitimidad al testimonio" (Feld, 2015, p. 705). Esto converge, además, con la reticencia de los gobiernos de la concertación de conservar la casa como lugar de la memoria, como ocurrió con la vivienda santiaguina de Londres 38, que logró este estatus por la presión de los familiares de detenidos-desaparecidos y las organizaciones sociales.

La primera toma pertenece a un pequeño baño con una claraboya como única salida de ventilación. Esta imagen da cuenta de las condiciones infrahumanas a las cuales se sometían a los prisioneros. Un solo lavatorio con medidas reducidas. Sin embargo, constituyó un resquicio para una intimidad abortada durante el resto del día, pues tenía un vidrio roto que permitía "ver la casa vecina, que se encontraba a escasos metros" (Guzmán, 20I4, p. 7I) y el patio con un ventanaárbol, y, por algunos momentos, se podía sentir la brisa fresca. "Lujos" mínimos para quienes sobrevivían entre el miedo, la tortura y el terror psicológico.

Como parte del agrupamiento de la "imagen superviviente" que expone lo que "seguirá siendo ineludiblemente fugaz, pasajero, transitorio" (Didi-Huberman, 2018, p. 423), esta fotografía del baño proporciona consistencia visual a los testimonios en los cuales se relatan las penurias de la

\footnotetext{
${ }^{8}$ De hecho, de acuerdo con Guzmán en la 'Presentación', el libro demoró en salir a solicitud de la víctima Alejandra Holzapfel, quien le pidió que esperara la muerte de su madre para publicarlo.
} 
vida en cautiverio, específicamente de aquella donde "el grado de perversidad al que llegaron los agentes era inimaginable para una mente medianamente sana” (Bataszew en Guzmán, 2014, p. 77). La placa fotográfica adquiere cuerpo propio ante la imposibilidad de la palabra de decir sobre lo sucedido, específicamente sobre los límites impuestos a la condición humana. Esta fotografía retrotrae a una parte de la dinámica que instaló la "nuda vida" en el contexto de dictadura militar, subrayando lo que anotó Kossoy (200I) acerca de "las [...] fuentes fotográficas como medios de información visual para la recuperación de los hechos pasados" (p. 27).

A esta foto la acompañan otras tres. Si la primera, una captura de la escalera hacia el segundo piso donde se torturaba, "presenta una disyunción estructural que hac[e] difícil considerar[1a] [...] como "prueba" (Feld, 2015, p. 699), las dos restantes imponen una "topografía en suspenso" sobre el sótano, acerca del cual testifica Alejandra Holzapfel: "Con el tiempo fui hasta ese lugar y me di cuenta que era un lugar muy chico, pero tenía una ventana y seguramente allí estaban los guardias y otros torturadores viendo cómo me torturaban" (en Guzmán, 2014, p. 69). Este desfase se debió a la situación de claustrofobia que la condenó a la carencia de referentes debido, en primer lugar, a la anulación de la visión por la venda sobre los ojos y, en segundo, del tacto por las ligaduras en las manos.

Con esto se origina un nodo que se resuelve sin tensión. A diferencia de las dos primeras imágenes, la del baño y la de la escalera, no existe constancia visual del sótano, parafraseando a Peris Blanes, no se tiene materialidad de la imagen sino un espacio que el lector cargará de significado a partir de los testimonios leídos. Con estas fotos se producirá en él una activación que acompañará, por ejemplo, la palabra de Bataszew y de Holzapfel: "Una llegaba a ese lugar y lo primero que le decían las compañeras era 'te pueden llevar al subterráneo y ahí hay un perro"' (Bataszew en Guzmán, 20I4, p. 86) y "Es horroroso, es algo que jamás se puede olvidar. Nunca he podido superar la humillación de ese momento" (Holzapfel en Guzmán, 20r4, p. 87). Aunque las imágenes no pueden hacerse cargo del vacío, de la "narrativa de muerte y desaparición" (Peris Blanes, 2017, p. 88) que aconteció allí, "se proyecta[n] espectralmente sobre ella" (p. 88) y se puede significar este lugar de deshumanización. Son visualidades supervivientes formando ciclos, que exhiben un suceso pasado en el presente y que "vuelve[n] a comenzar[lo] cada vez", como las definió Didi-Huberman (2018, p. 9, cursivas en el texto original), para que se produzcan nuevas aproximaciones a ese instante histórico y a un sujeto más allá de su propia contingencia.

En este libro, las testimoniantes reconocen la dificultad de hablar, "me cuesta mucho narrar lo que viví" (Holzapfel en Guzmán, 2014, p. 87) o "se nos ha dificultado que se vea en su 
magnitud lo que ahí sucedió" (Bataszew en Guzmán, p. 77), no obstante, aún entrecortadas o temerosas, sus palabras están, pueden leerse o escucharse," construidas desde "lo que vieron y pudieron reconocer posteriormente" (Feld, 2015, p. 707), pero las fotografías de la entrada hacia el sótano se potencian como fragmentos de la condición abyecta -tanto del acontecimiento mismo como del sitio- sobre la cual solo restan objetos menores para nombrarla, como las escaleras, en "ese proceso de 'actualización del pasado' [...] [pues] lo que queda es una imagen fotográfica, [...] [que] se convierte en el depósito y el garante de una presencia que ya no es" (Peris Blanes, 2017, p. 89), y donde la mirada significante del observador/lector se encargará de enmarcarla críticamente.

\section{"IMÁGENES SUPERVIVIENTES" CONTRA EL OLVIDO. A MANERA DE CIERRE}

Las imágenes abordadas complementan los testimonios en los libros de Rebolledo y Guzmán al revelar a los sujetos implicados en crímenes de lesa humanidad, que "se desencadenan en un momento histórico específico" (Kossoy, 200I, p. 33), y los lugares del horror que los gobiernos postdictadura han pretendido borrar, algunos con éxito, como la casa de la calle José Domingo Cañas donde estaba el Cuartel Ollagüe, demolida en 2002.

Como manifiesta Feld, "cada imagen presenta varias capas de visibilidad y estas se construyen con el tiempo, con las nuevas condiciones de enunciación, con las reediciones y con los contextos memoriales que se van sucediendo" (2015, p. 7II). Esta idea expone la fotografía documental como parte de un entramado que, en el corpus seleccionado, enriquece el testimonio, que coloca rostros y los particulariza en su responsabilidad, y que, para el presente, como bien analizó Peris Blanes (2009 y 2017), resignifica espacios donde acontecieron situaciones límite como la tortura.

Las series fotográficas con las caras de los torturadores y los instructores de Tejas Verdes complementan los testimonios, esos pliegos que, para Pizarro Cortés y Santos Herzeg (2019), "generan un anclaje histórico-referencial [...], y [que] contribuye[n] asimismo al delineamiento de una cartografía de la represión bajo la dictadura" (p. 253), al tiempo que los personalizan visualmente; mientras que las tomas de la casa conocida como la 'Venda Sexy', además de evidenciar las condiciones infrahumanas sufridas por los detenidos, sobre todo mujeres, pone de relieve la dificultad de aprehender en su totalidad el horror, pero que, no obstante, se puede dejar

\footnotetext{
9 Referencia al documental Los horrores de la Venda Sexy, en el cual ambas víctimas testimonian, disponible en: https://youtu.be/dbpM6QgBoYc (fecha de consulta: 24/o7/2020).
} 
una constancia, aun una mínima, una topografía en suspenso, como las fotos de las escaleras hacia el sótano.

Por último, pensando con Eltit (2014), una imagen puede irrumpir críticamente los pactos tejidos por un Estado que ha buscado el blanqueamiento de los sujetos y de los lugares incómodos, y que puja por silenciar, a través de una retórica del consenso, cualquier "figura social del miedo" (p. 54) capaz de desbaratar su narratología. Esos modos particulares de perdurar que instaura la fotografía documental en el caso de Rebolledo y Guzmán, que exhiben sin mediar la elaboración de un registro no facticio, resultan instancias que también se suman al "rigor, la verdad y la memoria" (Fontcuberta, 2015, p. I09), que conforman archivos y que, en la actualidad, desde su índole de traza, cuentan sobre el pasado, renaciéndolo una y otra vez para el presente. Son, en definitiva, las 'imágenes supervivientes', las formas obsesivas que arman un corpus de saber contra el olvido (DidiHuberman, 2018).

\section{REFERENCIAS}

Arendt, Hannah (2003). Eichmann en Jerusalén. Un estudio sobre la banalidad del mal. Lumen.

Didi-Huberman, Georges (2018). La imagen superviviente. Historia del arte y tiempo de los fantasmas según Aby Warburg. Abada.

Eltit, Diamela (2014). Emergencias. Seix Barral.

Feld, Claudia (20I5). Imagen y testimonio frente a la desaparición forzada de personas en la Argentina de la transición. Kamchatka, 6, 687-715. https://cutt.ly/nTtGlgu

Fontcuberta, Joan (2015). La cámara de Pandora. La fotografi@ después de la fotografía. Gustavo Gili.

Guzmán Jasmen, Nancy (2014). Ingrid Olderock. La mujer de los perros. Ceibo Ediciones.

Kossoy, Boris (200I). Fotografía e historia. La marca.

Peris Blanes, Jaume (2009). De la prueba documental a la evocación subjetiva. Usos de la fotografía en las publicaciones sobre la represión chilena. Pasajes de pensamiento contemporáneo, 30, 8596 https://cutt.ly/fTtGRuF

Peris Blanes, Jaume (2017). Testimonio y visualidad: de la visión del ciego a las imágenes del vacío. En Scarabelli, Laura y Cappellini, Serena (Eds.). DONDE NO HABITE EL OLVIDO. Herencia 


$y \quad$ transmisión del testimonio en Chile (pp. 77-92). Di/Segni
https://doi.org/I0.4000/books.ledizioni.8349

Pizarro Cortés, Carolina y Santos Herceg, José (2019). El campo testimonial chileno: una mirada de conjunto. Otras Modernidades, 2I, 246-267.

Rebolledo, Javier (2015). A la sombra de los cuervos. Los cómplices civiles de la dictadura. Planeta.

Rebolledo, Javier (2013). El despertar de los cuervos. Tejas Verdes el origen del exterminio en Chile. Ceibo Ediciones.

Rebolledo, Javier (2012). La danza de los cuervos. El destino final de los detenidos desaparecidos. Ceibo Ediciones.

S/A. Los horrores de la Venda Sexy. https://youtu.be/dbpM6QgBoYc 